Hirofumi Sueoka • Andrey Moshinetsky

Masayoshi Nagao • Shunzo Chiba

\title{
Mutation screening of phenylketonuria in the Far East of Russia
}

\begin{abstract}
We analyzed mutant genotypes at the human phenylalanine hydroxylase (PAH) locus among phenylketonuria (PKU) patients in the Far East of Russia. A total of 60 variant alleles from 30 PKU families were analyzed for prevalent Caucasian mutations and restriction fragment length polymorphism/variable number of tandem repeats (RFLP/VNTR) haplotypes. Seventy-eight percent of all variant alleles carried six mutations. The most prevalent mutation was R408W (63\%), with a haplotype background of 2.3. It also showed a very high degree of homozygosity (43\%). The other five mutations (R158Q, R261Q, R252W, R261X, and IVS12nt-1) accounted for $1.7 \%-6.7 \%$ of all PKU alleles, and a single haplotype was associated with each genotype, except for R261Q. The genetic structure of PKU patients in the Far East of Russia seems to be relatively homogeneous, compared with that in the other Slavic and Oriental populations of surrounding countries. Prediction of a clinical phenotype and carrier detection will be feasible using DNA tests.
\end{abstract}

Key words Phenylketonuria · Phenylalanine hydroxylase · Mutation screening $\cdot$ Far East of Russia

\section{Introduction}

Phenylketonuria (PKU [OMIM 261600]) is one of the most common genetic disorders among Caucasians and Chinese. A mass screening program for PKU has recently started in

H. Sueoka $\cdot$ M. Nagao $(\square)$

Department of Pediatrics, National Otaru Hospital, 3-24-1

Nagahashi, Otaru, Hokkaido 047-0036, Japan

Tel. +81-134-32-5131; Fax +81-134-29-2164

e-mail: CXQ04341@nifty.ne.jp

H. Sueoka $\cdot$ M. Nagao $\cdot$ S. Chiba

Department of Pediatrics, Sapporo Medical University, Sapporo, Japan

A. Moshinetsky

Far Eastern National Medical University, Institute of Motherhood and Childhood Protection, Khabarovsk, Russia the Far East of Russia. In the Khabarovsk district, $97.5 \%$ of newborns are investigated at the laboratory of Motherhood and Childhood Protection every year. In the period 1992 to 1997, PKU cards from 79,411 newborns were screened for the disorder in Khabarovsk, and 13 were diagnosed as having PKU. The estimated frequency of PKU in the region was $1: 6,100$, which is comparable to the value of $1: 6,500$ 7,000 among Russian populations (Moshinetsky et al. 1998). Nowadays, the patients are appropriately treated to prevent the central nervous system disorder.

Recent mutation analysis has revealed that the genetic background of PKU is different between Caucasians and Orientals. To date, more than 300 PKU mutations have been reported in the world (Nowacki et al. 1998). Although the molecular lesions present in the PAH genes have previously been determined among Russian populations in Moscow and Saint Petersburg (Charikova et al. 1993, Baranovskaya et al. 1996), little is known regarding the molecular basis of PKU in the Far East of Russia. The ethnic background in the region is predominantly Slavic ( $90 \%$ of the population), that originated in European Russia or in Eastern European countries. Tatars (1.8\%), Jews (1\%), and other small ethnic groups constitute the rest of the population. It is possible that there may have been multiple founding populations of PKU in this vast land. Therefore, the frequency of major mutations found among Caucasians, especially Slavs in Eastern Europe, and the geographic distribution or clustering of a particular PKU allele is expected to reveal the genetic structure of the phenylalanine hydroxylase $(P A H)$ gene. In this study, we analyzed the molecular basis of the disease in 30 PKU families from the Far East of Russia.

\section{Patients and methods}

Patients

A total of 30 unrelated PKU families from the Khabarovsk, Vladivostok, and Sakhalin districts were investigated 
(Fig. 1). The age of patients at DNA diagnosis ranged from 1 to 11 years. Twenty-six families were of Slavic ancestry, 1 was of Tatar ancestry, 1 was of mixed Slavic and Tatar ancestry, 1 was of Jewish ancestry, and 1 was of mixed Jewish and Slavic ancestry. Twenty-four patients were classified as having "classic PKU", 4 as "moderate PKU", and 1 as "mild PKU", based on initial phenylalanine levels in the blood and dietary phenylalanine tolerance, using the criteria described by Güttler (1980). Also, 1 patient was diagnosed as having a benign form of hyperphenylalaninemia (mild hyperphenylalaninemia). Informed consent was obtained for all subjects examined in the study.

\section{Haplotype analysis}

Genomic DNA was extracted from PKU cards according to the method of Jinks et al. (1989). The restriction fragment length polymorphism (RFLP)-haplotype of the $P A H$ gene was analyzed by Southern blotting (Kwok et al. 1985) and polymerase chain reaction (PCR)-RFLP (Dworniczak et al. 1991a,b; Goltsov et al. 1991; Wedemeyer et al. 1991; Scriver et al. 1993). The variable number of tandem repeats (VNTR)-haplotype at the Hind-III site was determined following the method of Golstov et al. (1992). Haplotypes were classified according to the standard nomenclature by Eisensmith and Woo (1992).

\section{Mutation analysis}

The different mutation-containing regions of the $P A H$ gene were amplified by PCR. Known mutations were screened using restriction enzyme digestion or the amplification re-

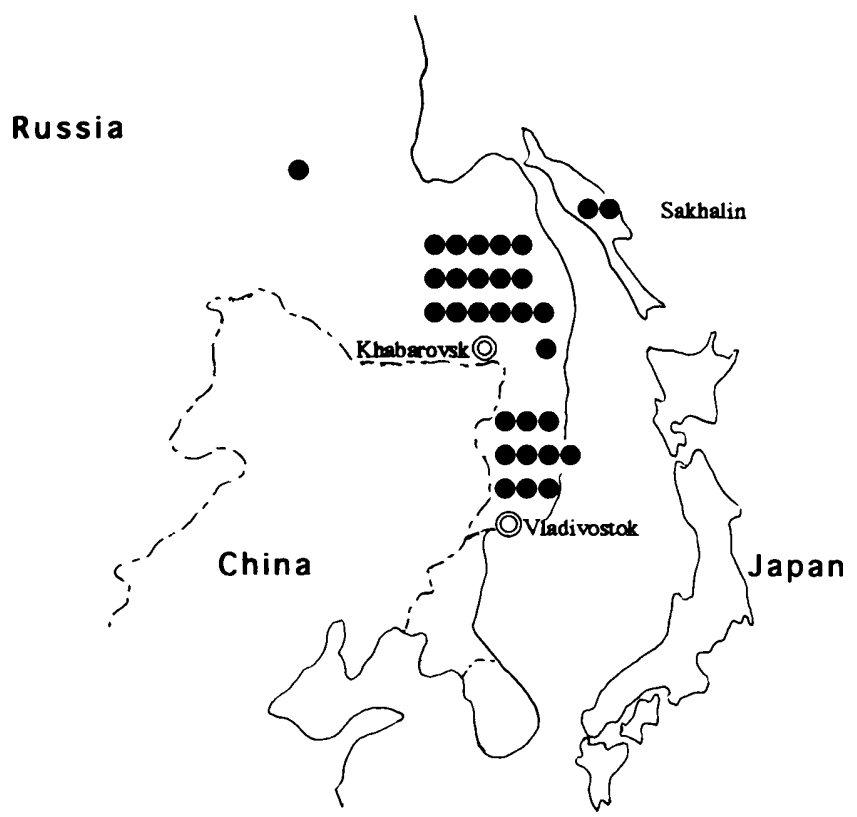

Fig. 1. Map of the Far East of Russia and geographic distribution of 30 phenylketonuria (PKU) families. Black circles denote the birthplace of each PKU patient in the present study fractory mutation system (ARMS). If the mutation was not encompassed by an existing sequence for the restriction enzyme, an artificial restriction site was introduced by PCR (amplification-created restriction sites, ACRS). Amplification primers and PCR protocols for the reported mutations were as described: R158Q (Dworniczak et al. 1989), IVS10nt546 (Dworniczak et al. 1991c), R408W (DiLella et al. 1987), R408Q (Eiken et al. 1992), Y414C (Okano et al. 1991), and IVS12nt-1 (DiLella et al. 1986). The R408W and IVS12nt-1 mutations were also detected by the ARMS (Sommer et al.1989). Mutations in exon 7 of the $P A H$ gene (R252W, R261Q, R261X, G272X, S273F et al.) were surveyed directly by the cycle-sequence method.

\section{Results}

In this study, a total of 60 variant alleles from 30 PKU patients was analyzed, using genomic DNAs from dried blood spots on PKU cards. Haplotype analysis of the $P A H$ gene was done by RFLP and VNTR analysis. Various mutations in the $P A H$ gene were determined by restriction enzyme digestion assay, ARMS, and direct sequencing. The frequencies and haplotypes of common PKU alleles are summarized in Table 1 . We showed that $78 \%$ of all variant alleles carry six mutations. The most prevalent mutation, $\mathrm{R} 408 \mathrm{~W}$, in which arginine at codon 408 was substituted with tryptophan, accounted for $63 \%$ of all PKU alleles. Of the 30 patients from the unrelated families, $13(43.3 \%)$ were homozygous for the R408W mutation, and $12(40 \%)$ were compound heterozygotes for the R408W mutation and other PKU alleles. The R408W allele was found only in the background of haplotype 2.3. The other mutations (R158Q, R252W, R261X, R261Q, and IVS12nt1) were detected at low frequencies $(1.7 \%-6.7 \%)$. A single haplotype was associated with each genotype, except for the R261Q mutation.

Many PKU mutations have been identified in exon 7 of the $P A H$ gene in previous studies. This is considered to be a reflection of the functional importance of the exon rather than a consequence of its being a mutation hot spot (Dworniczak et al. 1992). We therefore sequenced exon 7 if the genotype of both alleles could not be determined by

Table 1. Frequencies of PKU mutations in 60 variant PAH alleles from the Far East of Russia

\begin{tabular}{lclccl}
\hline Mutation & Exon & $\begin{array}{l}\text { Haplotype } \\
\text { (RFLP/VNTR) }\end{array}$ & $\begin{array}{c}\text { No. of } \\
\text { alleles }\end{array}$ & $\begin{array}{l}\text { Frequency } \\
(\%)\end{array}$ & Ethnic group \\
\hline R408W & 12 & 2.3 & 38 & 63.3 & Slavic, Jewish \\
R261Q & 7 & 2.3 & 3 & 5.0 & Tatar \\
& & 1.8 & 1 & 1.7 & Slavic \\
R158Q & 5 & 7.8 & 2 & 3.3 & Slavic \\
R252W & 7 & 7.8 & 1 & 1.7 & Slavic \\
R261X & 7 & 3.8 & 1 & 1.7 & Tatar \\
IVS12nt-1 & & 3.8 & 1 & 1.7 & Slavic \\
Total & & & 47 & 78.4 & \\
Unknown & & & 13 & 21.6 & \\
\hline
\end{tabular}


PCR with restriction enzyme digestion assay or ARMS. Two patients were found to be homozygous for the R261Q mutation in exon 7. One patient was a compound heterozygote of the R408W and R261X mutations and the R252W mutation was detected in a heterozygous form with an unidentified PKU allele in one patient. Since each nucleotide substitution creates a new restriction site or abrogates an existing one, it was possible to confirm the presence of three mutations by PCR-restriction enzyme assay: R252W (AvaI), R261Q (HinfI), and R261X (DdeI).

We could relate the clinical phenotype to the genotype in some patients. All patients homozygous for the R408W mutation showed a severe metabolic phenotype (classic PKU). R261Q homozygotes were clinically diagnosed as moderate PKU. Compound heterozygotes for the R408W mutation showed various phenotypes depending on the genotype of the other allele; R408W/IVS12nt-1 (classic), R408W/R261X (classic), and R408W/R158Q (mild). The R408W mutation was also identified in the patient with benign hyperphenylalaninemia; however, the genotype of the other allele could not be determined.

The genotype of 13 alleles $(21.6 \%)$ is still unknown after the mutation screening by PCR-restriction enzyme assay and direct sequencing of exon 7. Subsequent analysis using other methods, such as the PCR-single-strand conformation polymorphism (SSCP) technique coupled with sequencing of every exon, will be necessary for the complete genotyping of PKU alleles.

\section{Discussion}

In the present study, we have first shown the prevalence of representative PKU mutations in the Far East of Russia. The only prevalent mutation, R408W, may have occurred in Eastern Europe, and then spread and merged into the Slavic and Tatar populations. The mutation could have been maintained at a high frequency among the Far East Russian population during the eastward expansion of the Slavs. Although the prevalence is low, we should note that two mutations, R261Q and R261X, more frequently found in Tatar and Turkish populations, were detected in patients of Tatar ancestry (Table 1). On the other hand, Oriental PKU alleles, such as the R413P mutation, which has been described predominantly in northern China and Japan (Wang et al. 1991), were not detected at all (data not shown). To investigate the possibility of genetic mixture between Russian and Asian populations, we also need to determine the mutation profiles of surrounding regions in detail, including China.

The observed phenotype in our patients mostly matched the metabolic phenotype predicted by the PAH-mutation genotype. However, discrepancies were sometimes apparent with R158Q and R261Q mutations in the homoallelic state, and also in the functionally hemizygous state (Guldberg et al. 1998). It may be better to observe and monitor blood phenylalanine levels regularly for definitive diagnosis and appropriate treatment.

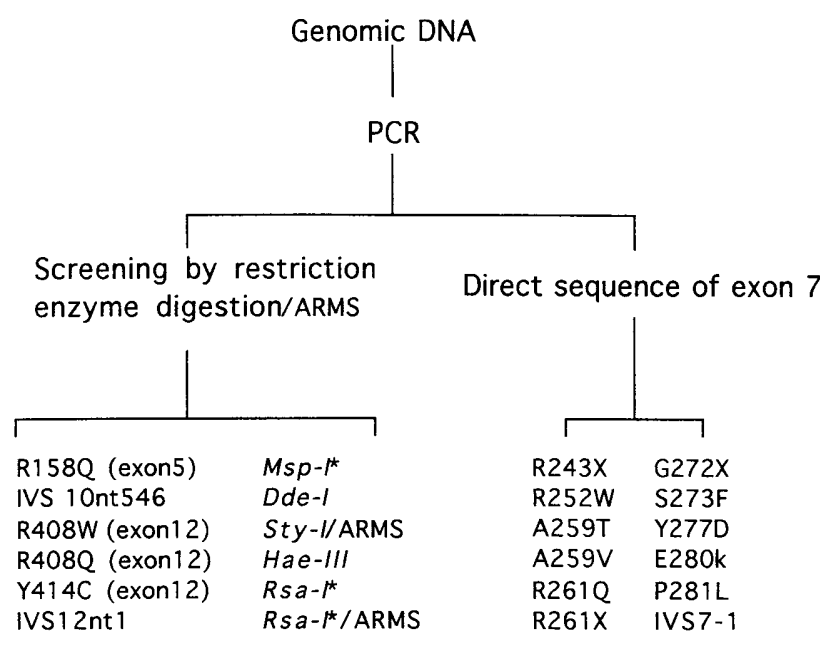

*Amplification created restriction site

Fig. 2. Strategy for detection of PKU mutations in the Far East Russian population. Genomic DNA was isolated from dried blood spots in PKU cards, and various mutation-containing regions of the phenylalanine hydroxylase $(P A H)$ gene were amplified by polymerase chain reaction $(P C R)$. Six mutations (R158Q, IVS-10nt546, R408W, R408Q, Y414C, and IVS-12nt1) were screened, using restriction enzyme digestion or amplification refractory mutation system (ARMS). When the genotype of both alleles could not be determined, exon 7 was amplified and sequenced

There have been a few reports on the mutation analysis of PKU among Slavic and non-Slavic populations of the former Soviet Union. The frequency of the R408W mutation among 31 unrelated PKU patients from the Moscow region (Charikova et al. 1993) was comparable to that found in the present investigation. They found that the R158Q and R261Q mutations were at low frequencies; however, the IVS12nt-1 mutation was more prevalent. This may be the effect of gene flow from the Northern European population into the Moscow region. In the Tatar Republic, the single major allele was R408W/RFLP haplotype 2/ VNTR 3, which was present on $78.6 \%$ of all mutant chromosomes of Slavic origin, but on only $37.0 \%$ of mutant chromosomes of Tatar origin (Kuzmin et al. 1995). In comparison with other European or Oriental populations, the genetic structure of our PKU patients seems to be homogeneous. The present results also suggest that it is technically feasible to develop a program for PKU-mutation screening among the Far East Russian population. Figure 2 shows the flow chart for the DNA test designed for Russian PKU patients. Six major mutations (R158Q, IVS10nt546, R408W, R408Q, Y414C, and IVS12nt-1) can be directly detected by the PCR-restriction digestion method or ARMS. Since exon 7 of the $P A H$ gene has a high possibility of carrying mutations, it is more efficient to sequence this exon from the beginning, instead of scanning several prevalent mutations. With these methods, we are expecting to identify more than $70 \%-80 \%$ of the PKU alleles in the Khabarovsk, Vladivostok, and Sakhalin districts. An intensive search for PKU mutations in other regions of Far East 
Russia will permit more effective molecular diagnosis and carrier screening.

Acknowledgments This work was supported by a Research Grant (8A-10) for Nervous and Mental Disorders from the Ministry of Health and Welfare of Japan. Dr. Moshinetsky was supported by the Foreign Scientist Exchange Program of Sapporo Medical University.

\section{References}

Baranovskaya S, Shevtsov S, Maksimova S, Kuzmin A, Schwartz E (1996) The mutations and VNTRs in the phenylalanine hydroxylase gene of phenylketonuria in St Petersburg. J Inher Metab Dis 19:705

Charikova EV, Khalchitskii SE, Antoshechkin AG, Schwartz EI (1993) Distribution of some point mutations in the phenylalanine hydroxylase gene of phenylketonuria patients from the Moscow region. Hum Hered 43:244-249

DiLella AG, Marvit J, Lidsky AS, Güttler F, Woo SLC (1986) Tight linkage between a splicing mutation and a specific DNA haplotype in phenylketonuria. Nature 322:799-803

DiLella AG, Marvit J, Brayton K, Woo SLC (1987) An amino acid substitution involved in phenylketonuria is in linkage disequilibrium with DNA haplotype 2. Nature 327:333-336

Dworniczak B, Aulehla-Scholz C, Horst J (1989) Phenylketonuria: detection of a frequent haplotype 4 allele mutation. Hum Genet 84:95-96

Dworniczak B, Wedemeyer N, Horst J (1991a) PCR detection of the BgIII RFLP at the human phenylalanine hydroxylase (PAH) locus. Nucleic Acids Res 19:1958

Dworniczak B, Wedemeyer N, Eigel A, Horst J (1991b) PCR detection of the PvuII (Ea) RFLP at the human phenylalanine hydroxylase (PAH) locus. Nucleic Acids Res 19:1958

Dworniczak B, Aulehla-Scholz C, Kalaydjieva L, Bartholome K, Grudda K, Horst J (1991c) Aberrant splicing of phenylalanine hydroxylase messenger RNA. The major cause for phenylketonuria in parts of Southern Europe. Genomics 11:242-246

Dworniczak B, Kalaydjieva L, Pankoke S, Aulehla-Scholz C, Allen G, Horst J (1992) Analysis of exon 7 of the human phenylalanine hydroxylase gene: a mutation hot spot? Hum Mutat 1:138-146

Eiken HG, Strangeland K, Skjekvale L, Knappskog PM, Boman H, Apold J (1992) PKU mutations R408W and F299C in Norway: haplotype associations, geographic distributions and phenotype characteristics. Hum Genet 88:608-612

Eisensmith RC, Woo SLC (1992) Updated listing of haplotypes at the human phenylalanine hydroxylase (PAH) locus. Am J Hum Genet 51:1445-1448
Goltsov AA, Eisensmith RC, Woo SLC (1991) Detection of the XmnI RFLP at the human PAH locus by PCR. Nucleic Acids Res 20:927

Goltsov AA, Eisensmith RC, Konecki DS, Lichter-Konecki U, Woo SLC (1992) Associations between mutations and a VNTR in the human phenylalanine hydroxylase gene. Am J Hum Genet 51:627-636

Guldberg P, Rey F, Zschocke J, Romano V, Francois B, Michiels L, Ullrich K, Hoffman GF, Burgard P, Schmidt H, Meli C, Riva E, Dianzani I, Ponzone A, Rey J, Güttler F (1998) A European multicenter study of phenylalanine hydroxylase deficiency: classification of 105 mutations and a general system for genotype-based prediction of metabolic phenotype. Am J Hum Genet 63:71-79

Güttler F (1980) Hyperphenylalaninemia: diagnosis and classification of the various types of phenylalanine hydroxylase deficiency in childhood. Acta Paediatr Scand (Suppl) 280:1-80

Jinks DC, Minter M, Tarver DA, Vanderford M, Hejtmancik JF, McCabe ERB (1989) Molecular genetic diagnosis of sickle cell disease using dried blood specimens on blotters used for newborn screening. Hum Genet 81:363-366

Kuzmin AI, Eisensmith RC, Goltsov AA, Sergeeva NA, Schwartz EI, Woo SLC (1995) Complete spectrum of PAH mutations in Tataria: presence of Slavic, Turkic and Scandinavian mutations. Eur J Hum Genet 3:246-255

Kwok SCM, Ledley FD, DiLella AG, Robson KJH, Woo SLC (1985) Nucleotide sequence of a full-length complementary DNA clone and amino acid sequence of human phenylalanine hydroxylase. Biochemistry 24:556-561

Moshinetsky A, Nagao M, Bazilevskaya E (1998) Phenylketonuria in Khabarovsk territory: neonatal frequency and genetic structure (abstract). In: Proceedings of the 6th international symposium of the Russian-Japan Medical Symposium, pp 127 August 24-25, Khabarovsk, Russia

Nowacki PM, Byck S, Prevost L, Scriver CR (1998) PAH mutation Analysis Consortium Database 1997: prototype for relational locusspecific mutation database. Nucleic Acids Res 26:220-225

Okano Y, Eisensmith RC, Dasovich M, Wang T, Güttler F, Woo SLC (1991) A prevalent missense mutation in Northern Europe associated with hyperphenylalaninemia. Eur J Pediatr 150:347-352

Scriver CR, Hoang L, Byck S, Prevost L (1993) PAH Gene Mutation Analysis Consortium Newsletter, December

Sommer SS, Cassady JD, Sobell JL, Bottema CDK (1989) A novel method for detecting point mutations or polymorphisms and its application to population screening for carriers of phenylketonuria. Mayo Clin Proc 64:1361-1372

Wang T, Okano Y, Eisensmith RC, Harvey ML, Lo WHY, Huang S-Z, Zeng Y-T, Yuan L-F, Furuyama J, Oura T, Sommer SS, Woo SLC (1991) Founder effect of a prevalent phenylketonuria mutation in the Oriental population. Proc Natl Acad Sci USA 88:2146-2150

Wedemeyer N, Dworniczak B, Horst J (1991) PCR detection of the MspI (Aa) RFLP at the human phenylalanine hydroxylase (PAH) locus. Nucleic Acids Res 19:1959 